Published in final edited form as:

Clin Lab Med. 2010 March ; 30(1): 311-328. doi:10.1016/j.cll.2010.01.003.

\title{
Lyme Disease
}

\section{Thomas S. Murray, MD PhD ${ }^{1}$ and}

Associate Research Scientist of Pediatrics and Laboratory Medicine, Yale University School of Medicine

Eugene D. Shapiro, MD ${ }^{2}$

Professor of Pediatrics, Epidemiology and Public Health and Investigative Medicine, Yale University School of Medicine

\section{Synopsis}

Lyme disease, caused by spirochete Borrelia burgdorferi, is the most common vector-borne disease in the United States. The clinical presentation varies depending on the stage of the illness: early disease includes erthyma migrans, early disseminated disease includes multiple erythema migrans, meningitis, cranial nerve palsies and carditis; late disease is primarily arthritis. The symptoms and signs of infection resolve in the vast majority of patients after appropriate treatment with antimicrobials for from 2-4 weeks. Serologic testing should be used judiciously as it often results in misdiagnosis when performed on blood from patients with a low prior probability of disease and those with non-specific symptoms such as fatigue or arthralgia without signs of infection.

\section{Keywords}

Lyme Disease; Borrellia burdorferi; tick-borne infections; erythema migrans; serologic testing; misdiagnosis

\section{Overview}

Lyme disease, caused by spirochete Borrelia burgdorferi, is the most common vector-borne disease in the United States. The clinical presentation varies depending on the stage of the illness and includes erthyma migrans, carditis, central nervous system disease, and arthritis. Regardless of the clinical presentation, most patients with Lyme disease have resolution of their clinical symptoms when treated with appropriate antimicrobials. Persistent symptoms after therapy are most often due to misdiagnosis rather than treatment failure. Although Lyme disease is a public health concern, extensive publicity has resulted in a degree of anxiety about Lyme disease that is out of proportion to the actual morbidity that it causes.

\footnotetext{
(c) 2010 Elsevier Inc. All rights reserved.

${ }^{2}$ Corresponding Author: mailing address: Department of Pediatrics, 333 Cedar Street, P.O. Box 208064, New Haven, CT 06520-8064, Phone: 203-688-4555 Fax: 203-785-3932, Eugene.Shapiro@Yale.edu.

1 mailing address: Department of Pediatrics, 333 Cedar Street, P.O. Box 208064, New Haven, CT 06520-8064, Phone: 203-785-4730, thomas.s.murray@Yale.edu
}

Publisher's Disclaimer: This is a PDF file of an unedited manuscript that has been accepted for publication. As a service to our customers we are providing this early version of the manuscript. The manuscript will undergo copyediting, typesetting, and review of the resulting proof before it is published in its final citable form. Please note that during the production process errors may be discovered which could affect the content, and all legal disclaimers that apply to the journal pertain. 


\section{Microbiology}

Lyme disease is caused by the spirochete, Borrelia burgdorferi sensu lato, a fastidious, microaerophilic bacterium that replicates slowly and requires special media to grow in the laboratory (Figure 1) [1]. The organism has been subclassified into several genomospecies, including B. burgdorferi sensu stricto, B. garinii, B. afzelii and others. Different genomospecies seem to be associated with an increased likelihood of certain specific manifestations of Lyme disease - for example, B. burgdorferi sensu stricto seems to have a prediction to cause arthritis (if not treated early), while $B$. garinii seems to be associated with an increased risk of neurologic manifestations of Lyme disease. In the United States only B. burgdorferi sensu stricto has been isolated from humans. In contrast, there is substantial variation in the genomospecies of $B$. burgdorferi sensu lato isolated from humans in Europe.

\section{Epidemiology}

Most cases of Lyme disease in the United States occur in southern New England, southeastern New York, New Jersey, eastern Pennsylvania, eastern Maryland, Delaware, and parts of Minnesota, Wisconsin and Michigan. More than three-quarters of these cases occur in fewer than 70 counties, an indication of the geographic limitation of the disease (Figure 2) [2]. Information about the true incidence of the disease is complicated by reliance on passive reporting of cases as well as by the high frequency of misdiagnosis [3,4]. In the most highly endemic areas of the United States, such as Connecticut, the incidence is about 0.5 cases $/ 1000$, but can be substantially higher in local areas. The incidence is highest in children 5-10 years of age, nearly twice as high as the incidence among adults.

In Europe, most cases occur in the Scandinavian countries and in central Europe (especially in Germany, Austria and Switzerland), although cases have been reported from throughout the region, including the United Kingdom (where many cases occur in the South Downs or New Forest areas).

B. burgdorferi is transmitted by Ixodid ticks-in the United States, primarily by Ixodes scapularis, the deer tick (Figure 3) [1]. Ixodid ticks must be distinguished from other common endemic ticks such as the dog tick (Figure 4). Other vectors include Ixodes ricinus (the sheep tick), Ixodes persulcatus and Ixodes pacificus in Europe, Asia, and the Pacific coast of the United States, respectively. Ixodid ticks have a 2-year, three-stage life cycle (Figure 5). The larvae hatch in the early summer and are usually not infected with $B$. burgdorferi. The tick may become infected at any stage of its life cycle by feeding on a host that is a natural reservoir for B. burgdorferi, usually a small mammal such as the whitefooted mouse (Peromyscus leucopus) (Figure 6). The larvae overwinter and emerge the following spring in the nymphal stage, which is the stage of the tick that is most likely to transmit the infection [5]. Nymphs molt to become adults in the fall. Adult females, which often spend the winter attached to large animals such as deer or sheep (hence the names-deer or sheep tick), lay their eggs the following spring before they die, and the 2-year life cycle begins again.

A number of factors are associated with the risk of transmission of B. burgdorferi from ticks to humans. First, the tick must be infected. The proportion of infected ticks varies greatly both by geographic area and by the stage of the tick in its life cycle. Lyme disease is uncommon in the Pacific states since few Ixodes pacificus ticks are infected with $B$. burgdorferi, in part because the serum of lizards, one of its major hosts, kills $B$. burgdorferi [6]. By contrast, in highly endemic areas of southern New England rates of infection of $I$. scapularis are, approximately, $2 \%$ for larvae, $15-30 \%$ for nymphs and $30-50 \%$ for adult ticks [1]. 
There has been substantial variation in rates of infection of Ixodes ricinus in reports from various European countries, but approximate averages are 10\% for nymphs and $20 \%$ for adult ticks [7].

Based on studies with experimental animals, to transmit $B$. burgdorferi, an infected tick generally must feed for 48-72 hours or longer [8]. These experimental findings were confirmed in a study in humans in which the risk of transmission from ticks (for which the duration of feeding could be assessed) to humans was $25 \%$ for nymphal ticks that had fed for at least 72 hours and $0 \%$ for nymphal ticks that had fed for $<72$ hours [5]. The bacteria live in the mid-gut of the tick, which needs to become engorged with blood (Figure 7) before the bacteria migrate to the salivary glands and the saliva, through which the organism is injected into the host. Persons with occupational, recreational or residential exposure to tickinfested fields, yards or woodlands in endemic areas are at increased risk of developing Lyme disease.

\section{Clinical Presentation}

The clinical manifestations of Lyme disease are classified into stages-early localized disease, early disseminated disease, and late disease (Table 1) [9,10]. Erythema migrans, the manifestation of early localized disease, appears at the site of the tick bite, 3 to 30 days (typically within 7 to 14 days) after the bite. In the United States, erythema migrans (single or multiple) is found in about $90 \%$ of patients with objective evidence of infection with $B$. burgdorferi [11-13].

The lesion begins as a red macule or papule and expands for days to weeks to form a large, annular, erythematous lesion that is at least $5 \mathrm{~cm}$ and as much as $70 \mathrm{~cm}$ in diameter (median of $15 \mathrm{~cm}$ ) (Figure 8). Most often, the rash is uniformly erythematous or it may appear as a target lesion with variable degrees of central clearing (Figure 8). It can vary greatly in shape, and, occasionally, may have vesicular or necrotic areas in the center. Erythema migrans is usually asymptomatic but may be pruritic or painful, and it may be accompanied by systemic findings such as fever, malaise, headache, regional lymphadenopathy, stiff neck, myalgia, or arthralgia.

The most common manifestation of early disseminated Lyme disease in the United States is multiple erythema migrans. The secondary skin lesions, which usually appear from 3 to 5 weeks after the tick bite, consist of multiple annular erythematous lesions similar to, but usually smaller than, the primary lesion. Other common manifestations of early disseminated Lyme disease are cranial nerve palsies, especially facial nerve palsy, and meningitis (sometimes accompanied by papilledema and increased intracranial pressure). Systemic symptoms such as fever, myalgia, arthralgia, headache, and fatigue are also common in this stage of Lyme disease. Carditis, which usually is manifest as a prolonged PR interval or, sometimes, complete heart block, is a rare manifestation of early, disseminated disease (Figure 9). Patients may present with fatigue, dizziness or syncopal episodes. Although it occurs only rarely in the United States, borrelial lymphocytoma, an inflammatory infiltrate that typically occurs in the ear lobe or the breast, is seen with some frequency in patients with Lyme disease in Europe. Likewise, meningoradiculoneuritis (Bannwarth's syndrome), a sometimes painful radiculopathy due to Lyme disease, is far more common in Europe than in the U.S.

The most common manifestation of late Lyme disease, which occurs weeks to months after the initial infection, is arthritis. The arthritis is usually monoarticular but may also be oligoarticular and primarily affects the large joints, particularly the knee. Although the affected joint is typically swollen and somewhat tender, the intense pain associated with a septic arthritis usually is not present. However, Lyme arthritis can be difficult to distinguish 
from septic arthritis [14]. Encephalitis, encephalopathy, and polyneuropathy are also manifestations of late Lyme disease, but they are very rare in children. Acrodematitis chronica atrophicans, a chronic sclerosing dermatitis, is an uncommon manifestation of Lyme disease in Europe but is virtually unknown in the United States.

Small numbers of case reports, most of which involved women with unrecognized and untreated Lyme disease during their pregnancies, suggested B. burgdorferi may be transmitted across the placenta and that congenital Lyme disease was associated with poor outcomes [15]. Although spirochetes compatible with B. burgdorferi were seen in pathologic specimens, B. burgdorferi was never isolated in culture from any of these cases. Several subsequent studies, designed to assess the potential link between Lyme disease during pregnancy and congenital infection with $B$. burgdorferi, found no documented $B$. burgdorferi infections of either the fetus or the infant [16]. Additional studies found no difference in birth outcomes comparing seropositive and seronegative pregnant women $[17,18]$. Likewise, a survey of neurologists in endemic areas found no evidence of any credible cases of congenital Lyme disease [19]. Transmission of Lyme disease via breastfeeding has also not been documented.

\section{Pathogenesis}

Information about the pathogenesis of Lyme disease comes from both human studies and animal models. B. burgdorferi express outer surface proteins (Osps) that are important for both survival in the tick and for infection in humans. OspA is required for B. burgdorferi adherence to the tick midgut [20,21]. Its expression decreases during engorgement as the spirochete leaves the midgut for the salivary glands and subsequent injection into the mammalian host. During this period, the expression of OspC increases; it has been postulated that OspC plays a role in migration of and infection by the spirochete [20]. The spirochete's ability to spread through skin and other tissues may be facilitated by the binding of OspC to human plasminogen [22]. This dissemination from the site of the tick bite, via the bloodstream, produces the systemic systems that may be associated with early Lyme disease as well as the clinical manifestations of early disseminated and, ultimately, of late Lyme disease.

In humans with erythema migrans, infiltrates of macrophages and of $\mathrm{T}$ cells produce both inflammatory and anti-inflammatory cytokines [23]. There is also evidence that in disseminated infections, adaptive T-cell and B-cell responses in lymph nodes produce antibodies against many components of the spirochete [24,25]. During dissemination within humans, B. burgdorferi attaches to certain host integrins [26,27] eliciting a proinflammatory response [28], that includes production of both matrix glycosaminoglycans, and extracellular-matrix proteins $[29,30]$ which may explain the organism's tropisms for particular tissues (e.g., collagen fibrils in the extracellular matrix in the heart, nervous system, and joints) [29].

Animal models have provided information about the clinical manifestations and immune response during early, disseminated disease including neuroborreliosis and carditis. Studies in mice have clearly demonstrated the importance of inflammatory innate immune responses in controlling early, disseminated Lyme disease [31,32]. After infection with B.burgdorferi, mice that lack either toll-like receptor 2, a part of the innate immune system, or the toll-like receptor adaptor, MyD88, have higher bacterial loads and more severe arthritis than isogenic wild type mice $[33,34]$. The role of complement in controlling infection has also been well described. Mice that lack $\mathrm{C} 3$ have increased numbers of spirochetes when infected; moreover, B.burgdoferi produces specific proteins that inhibit complement activity which facilitates infection [20]. A C3H mouse model of Lyme carditis has been developed in 
which cardiac infiltrates of both macrophages and $\mathrm{T}$ cells produce inflammatory cytokines [35]. In these mice, the killing of spirochetes through cellular immune mechanisms appears to be the dominant factor in the resolution of cardiac disease [36].

A nonhuman, primate animal model of neuroborreliosis has been developed to try to better understand the spread of B. burgdorferi within the nervous system [37]. In immunosuppressed monkeys with an exceptionally large inoculum of bacteria, $B$. burgdorferi infiltrated the leptomeninges, the motor and sensory nerve roots, and the dorsalroot ganglia, but not the brain parenchyma [38]. B. burgdorferi also infiltrated the perineurium (the connective tissue sheath surrounding each bundle of peripheral-nerve fibers) in the peripheral nervous system of these monkeys.

Studies of patients with clinical manifestations of late disease, specifically Lyme arthritis, have confirmed observations in animals that the host immune response is important for the pathogenesis of disease. Synovial tissue from patients with Lyme arthritis typically shows synovial hypertrophy, vascular proliferation, and a marked mononuclear cell infiltrate. Sometimes pseudolymphoid follicles are present that resemble peripheral lymph nodes [39]. During acute Lyme arthritis, innate immune responses to B. burgdorferi lipoprotein, as well as marked adaptive immune responses to many spirochetal proteins, are found [40-42]. Both Th- 1 and Th-2 dependent cytokines are found in the joint fluid [43,44]. In addition, patients with Lyme arthritis typically have higher Borrelia-specific antibody titers than do patients with other manifestation of Lyme disease [40,45]. Some adult patients with Lyme arthritis, particularly those with HLA-DRB1 alleles, will develop a chronic, antibiotic treatmentresistant, autoimmune arthritis [46,47].

\section{Diagnosis}

The diagnosis of Lyme disease, especially in the absence of the characteristic rash, may be difficult, since the other clinical manifestations of Lyme disease are not specific. Even the diagnosis of erythema migrans sometimes may be difficult, since the rash initially may be confused with nummular eczema, granuloma annulare, an insect bite, ringworm, or cellulitis. The relatively rapid and prolonged (untreated, it lasts for weeks) expansion of erythema migrans helps to distinguish it from these other conditions.

The sensitivity of culture for $B$. burgdorferi is only fair and special media are required; moreover, it is necessary for patients to undergo an invasive procedure to obtain appropriate tissue or fluid for culture. Consequently, such tests are indicated only in rare circumstances. Likewise, diagnostic tests that are based on the identification of antigens of B. burgdorferi, including the polymerase chain reaction (PCR), have not been shown to be sufficiently accurate to be clinically useful under non-experimental conditions. Although studies in research laboratories suggest that the PCR test is promising, contamination is a potential problem in commercial laboratories and an invasive procedure is still necessary to obtain appropriate material to test. Consequently, the confirmation of Lyme disease by the laboratory usually rests on the demonstration of antibodies to B. burgdorferi in the patient's serum.

It is well documented that the sensitivity and specificity of antibody tests for Lyme disease vary substantially [48]. The accuracy and reproducibility of pre-packaged commercial kits is much poorer than that of tests performed by "reference" laboratories that maintain tight quality control and regularly prepare the materials that are used in the test. Official recommendations from the Second National Conference on Serologic Diagnosis of Lyme Disease and from the CDC are that clinicians use a two-step procedure when ordering antibody tests for Lyme disease-first, a sensitive screening test, such as an enzyme-linked immunosorbent assay (ELISA) and, if that result is positive or equivocal, a Western 
immunoblot (a more specific test than the ELISA) to confirm the result [10,49]. If the ELISA result is negative, an immunoblot is not indicated. Immunoblots should not be ordered without a simultaneously ordered ELISA. The ELISA provides a quantitative estimate of the concentration of antibodies against $B$. burgdorferi. The immunoblot provides information about the specificity of the antibodies; positive "bands" mean that antibodies against specific protein antigens of $B$. burgdorferi are present. Most authorities require the presence of antibodies against at least either 2 (for $\operatorname{IgM}$ ) or 5 (for $\operatorname{IgG}$ ) specific proteins of B. burgdorferi for the immunoblot to be considered positive (Figure 10) [10,49]. Antibody test results are not useful for the diagnosis of early localized Lyme disease, since only a minority of patients with single erythema migrans will have a positive test result because the rash usually develops before the antibodies are detectable. A diagnosis of Lyme disease should not be based on a positive IgM result alone in patients who have had symptoms for $\geq 4$ weeks [9].

\section{Misdiagnosis}

It is critically important to understand that the predictive value of antibody test results, even of very accurate tests, is highly dependent on the prevalence of the infection among patients who are tested (Table 2) [50]. Antibody tests for Lyme disease should not be used as screening tests [50,51]. Unfortunately, because many lay persons (as well as physicians) have the erroneous belief that chronic, nonspecific symptoms alone (e.g., fatigue or arthralgia) may be manifestations of Lyme disease, patients with only nonspecific symptoms are frequently tested for Lyme disease. Lyme disease will be the cause of the nonspecific symptoms in very few such patients, if any. However, because the specificity of even the best antibody tests for Lyme disease is nowhere near $100 \%$, some of the test results in patients without specific signs or symptoms of Lyme disease will be falsely positive (Table 2) [50,51]. Nevertheless, an erroneous diagnosis of Lyme disease frequently is made and such patients often are treated unnecessarily with antimicrobials [52].

Clinicians should realize that even though a symptomatic patient has a positive serologic test result for antibodies to $B$. burgdorferi, it is possible that Lyme disease may not be the cause of that patient's symptoms. In addition to the possibility that it is a false-positive result, the patient may have been infected with $B$. burgdorferi previously, and the patient's current symptoms may be unrelated to that previous infection. Once serum antibodies to $B$. burgdorferi do develop, both $\operatorname{IgG}$ and $\operatorname{IgM}$ may persist for many years despite adequate treatment and clinical cure of the illness [53,54]. There is no indication to recheck serology after therapy to determine the effectiveness of treatment. In addition, because some people who become infected with $B$. burgdorferi never develop symptoms, in endemic areas there will be a background rate of seropositivity among patients who have never had clinically apparent Lyme disease. Physicians should not routinely order antibody tests for Lyme disease either for patients who have not been in endemic areas or for patients with only nonspecific symptoms.

\section{Differential Diagnosis}

The differential diagnosis of Lyme disease varies depending on the stage of disease. Erythema migrans, the rash of early Lyme disease, must be differentiated from inflammation associated with insect bites, nummular eczema, granuloma annulare, ringworm, and cellulitis. Other causes of carditis include viral agents, specifically Coxsackie enteroviruses. The differential diagnosis for arthritis is long and includes bacterial septic arthritis, rheumatologic, and oncologic processes.

Ixodes ticks may transmit other pathogens in addition to B. burgdorferi, including Babesia, Anaplasma, other Borrelia species, and viruses $[1,10]$. These agents may be transmitted 
either separately from or simultaneously with $B$. burgdorferi. Patients should be evaluated for these organisms if they have physical or laboratory findings suggestive of these diseases.

\section{Treatment}

Guidelines for antimicrobial therapy for specific stages of Lyme disease have been published by the Infectious Disease Society of America (Tables 1,3) [10]. Early disease characterized by erythema migrans is best treated orally with doxycycline or amoxicillin for 14 days, although there is some evidence that 10 days of therapy may be adequate. Early disseminated disease diagnosed as either a localized cranial nerve palsy, multiple erythema migrans, or carditis in outpatients without complete heart block can also be treated with oral agents. Late disease, manifesting as arthritis, typically responds well to oral therapy with either doxycycline or amoxicillin. Additional treatment with non-steroidal antiinflammatories may also provide symptomatic benefit to the patient.

Intravenous therapy with ceftriaxone is often used for Lyme meningitis. However, data from Europe shows that oral doxycycline is as effective as ceftriaxone for Lyme meningitis [55]. Another indication for ceftriaxone is myocarditis and heart block in symptomatic patients requiring hospitalization [10]. As symptoms improve, these patients can complete therapy with an oral agent.

Few clinical trials of treatment for Lyme disease have been conducted in children [56]. Most recommendations for the treatment of children are extrapolated from studies of adults. Children younger than 8 yrs of age should not be treated with doxycycline because it may cause permanent discoloration of their teeth. Patients who are treated with doxycycline should be alerted to the risk of developing dermatitis in sun-exposed areas while taking the medication. Cefuroxime is also approved for the treatment of Lyme disease and is an alternative for persons who cannot take doxycycline and who are allergic to penicillin. Azithromycin is less efficacious than other oral agents and should only be used when there is a clear contraindication to the preferred antimicrobials. There is little need to use newer agents because the results of treatment with either amoxicillin or doxycycline have been excellent.

Some patients may develop a Jarisch-Herxheimer reaction soon after treatment is initiated. The manifestations of this reaction are increased temperature, sweats, and myalgia. These symptoms resolve spontaneously within $24-48 \mathrm{hr}$, although administration of nonsteroidal anti-inflammatory drugs often is beneficial. Antimicrobial treatment during a JarischHerxheimer reaction should not be discontinued.

\section{Prognosis}

The long-term prognosis for individuals who are treated with appropriate antimicrobial therapy for Lyme disease, regardless of the stage of the disease, is excellent. The most common reason for a lack of response to appropriate antimicrobial therapy for Lyme disease is misdiagnosis (i.e., the patient actually does not have Lyme disease). Nonspecific symptoms (such as fatigue, arthralgia or myalgia) may persist for several weeks even in successfully treated patients with early Lyme disease; their presence should not be regarded as an indication for additional treatment with antimicrobials. These symptoms usually respond to non-steroidal anti-inflammatory agents. Within a few months of completing the initial course of antimicrobial therapy, these vague, nonspecific symptoms will usually resolve without additional antimicrobial therapy. For those unusual patients who have persistent symptoms more than six months after the completion of antimicrobial therapy, an attempt should be made to determine if these symptoms are the result of a post-infectious phenomena or of another illness. 
Klempner and coworkers recently reported the results of two controlled trials of antibiotic treatment for adult patients with chronic musculoskeletal pain, neurocognitive symptoms, or both that persisted after antibiotic treatment for Lyme disease [57]. One study included patients who were seropositive for $\operatorname{IgG}$ antibodies to B. burgdorferi at the time of enrollment; the other study included patients who were seronegative. In both studies, patients were randomly assigned to receive either ceftriaxone administered intravenously for 30 days followed by doxycycline orally for 60 days or matching regimens with intravenous and oral placebos. There were no significant differences in the outcomes of patients treated with antibiotics compared with those treated with placebo among either the seropositive or the seronegative patients. Of note, nearly $40 \%$ of subjects treated with placebo improved. These findings support earlier recommendations that such patients are best treated symptomatically rather than with prolonged courses of antibiotic therapy, which have been associated with serious adverse side effects [58]. Additional clinical studies of these patients confirm that the risks of long term treatment far outweigh any possible benefits [59].

\section{Prevention of Lyme Disease}

Reducing the risk of tick bites is one obvious strategy to prevent Lyme disease [60]. In endemic areas, clearing brush and trees, removing leaf litter and woodpiles, and keeping grass mowed may reduce exposure to ticks. Recent data demonstrates the application of acaricide to white tailed deer prevent feeding by ticks, reducing the risk for tick-borne disease [61]. Application of pesticides to residential properties is effective in suppressing populations of ticks, but may be harmful both to other wildlife and to people.

Tick and insect repellents that contain n,n-diethylmetatoluamide (DEET) applied to the skin provide additional protection, but require reapplication every 1 to 2 hours for maximum effectiveness. Serious neurologic complications in children from either frequent or excessive application of DEET-containing repellents have been reported, but they are rare and the risk is low when these products are used according to instructions on their labels. Use of products with concentrations of DEET greater than $30 \%$ is not necessary and increases the risk of adverse effects. DEET should be applied sparingly only to exposed skin, but not to the face, hands, or skin that is either irritated or abraded. After one returns indoors, skin that was treated should be washed with soap and water. Permethrin (a synthetic pyrethroid) is available in a spray for application to clothing only and is particularly effective because it kills ticks on contact.

Because most persons (approximately 75\%) who recognize that they were bitten by a tick remove the tick within 48 hours, the risk of Lyme disease from recognized deer tick bites is low-approximately 1-3\% in areas with a high incidence of Lyme disease. Indeed, the risk of Lyme disease is higher for unrecognized bites (since such ticks will feed for a longer time). Persons should be taught to inspect themselves and their children's bodies and clothing daily after possible exposure to Ixodid ticks. An attached tick should be grasped with fine-tipped tweezers as close to the skin as possible and removed by gently pulling the tick straight out. If some of the mouth parts remain embedded in the skin, they should be left alone, since they usually are extruded eventually; additional attempts to remove them often result in unnecessary damage to tissue and may increase the risk of local bacterial infection. Analysis of ticks to determine whether they are infected is not indicated because it is unclear how these test results correlate with the probability of human disease. No vaccine for Lyme disease is currently available.

A study of antimicrobial prophylaxis for ticks bites among adults found that a single, 200 $\mathrm{mg}$ dose of doxycycline was $87 \%$ effective in preventing Lyme disease, although the $95 \%$ confidence interval around this estimate of efficacy was wide (the lower bound was $25 \%$ or 
less, depending on the method used) [5]. In that study, the only persons who developed Lyme disease had been bitten by nymphal stage ticks that were at least partially engorged; the risk of Lyme disease in this group was 9.9\% (among recipients of placebo), while it was $0 \%$ for bites by all larval and adult deer ticks. Unfortunately, the expertise to identify the species, stage and degree of engorgement of a tick, and thereby to assess the degree of risk, is rarely available to persons who are bitten. Consequently, routine use of antimicrobial agents to prevent Lyme disease in persons who are bitten by a deer tick, even in highly endemic areas, is not generally recommended because the overall risk of Lyme disease is low (1-3\%), only doxycycline (which is not recommended for children < 8 years of age) has been shown to be effective and treatment for Lyme disease, if it does develop, is very effective [62].

\section{Summary}

Lyme disease is caused by the spirochete Borrelia burgdorferi, injected into the blood stream after an infected tick has been attached $48-72 \mathrm{hrs}$. It can manifest as early localized disease (erythema migrans), early disseminated disease (e.g meningitis or multiple erythema migrans), or late disease (large joint arthritis). Both the innate and adaptive immune systems contribute to the inflammatory response which results in clinical symptoms. Regardless of the clinical presentation, the vast majority of patients who are treated for Lyme disease with short courses of appropriate antibiotics do extremely well. Serologic testing for Lyme disease is imperfect and should be reserved for patients from endemic areas with a clinical syndrome and physical findings consistent with Lyme disease. Preventive measures such as, checking for and removing ticks after extensive time outdoors, wearing of pants and longsleeved shirts, and the application of tick repellant potentially can reduce the risk of Lyme disease for individuals with increased exposure to ticks.

\section{Acknowledgments}

This publication was supported in part by CTSA Grants Number UL1 RR024139, KL2 RR024138, and K24RR022477 (E.D.S.) from the National Center for Research Resources a component of the National Institutes of Health (NIH), and NIH Road map for Medical Research and K08 AI 071074 (T.S.M.). Its contents are solely the responsibility of the authors and do not necessarily represent the official view of NCRR or NIH. Information on Reengineering the Clinical Research Enterprise can be obtained from the NIH web site.

\section{Refererences}

1. Shapiro ED, Gerber MA. Lyme disease. Clin Infect Dis. Aug; 2000 31(2):533-542. [PubMed: 10987718]

2. Centers for Disease Control and Prevention. Lyme Disease-United States 2001-20021. MMWR. 2004; 53:365-369. [PubMed: 15129194]

3. Steere AC, Taylor E, McHugh GL, et al. The overdiagnosis of Lyme disease. Jama. Apr 14; 1993 269(14):1812-1816. A. [PubMed: 8459513]

4. Reid MC, Schoen RT, Evans J, et al. The consequences of overdiagnosis and overtreatment of Lyme disease: an observational study. Ann Intern Med. Mar 1; 1998 128(5):354-362. [PubMed: 9490595]

5. Nadelman RB, Nowakowski J, Fish D, et al. Prophylaxis with single-dose doxycycline for the prevention of Lyme disease after an Ixodes scapularis tick bite. N Engl J Med. Jul 12; 2001 345(2): 79-84. [PubMed: 11450675]

6. Ullmann AJ, Lane RS, Kurtenbach K, et al. Bacteriolytic activity of selected vertebrate sera for Borrelia burgdorferi sensu stricto and Borrelia bissettii. J Parasitol. Dec; 2003 89(6):1256-1257. [PubMed: 14740924]

7. Rauter C, Hartung T. Prevalence of Borrelia burgdorferi sensu lato genospecies in Ixodes ricinus ticks in Europe: a metaanalysis. Appl Environ Microbiol. Nov; 2005 71(11):7203-7216. [PubMed: 16269760] 
8. Piesman J, Mather TN, Sinsky RJ, et al. Duration of tick attachment and Borrelia burgdorferi transmission. J Clin Microbiol. Mar; 1987 25(3):557-558. B. [PubMed: 3571459]

9. Steere AC. Lyme disease. N Engl J Med. Jul 12; 2001 345(2):115-125. [PubMed: 11450660]

10. Wormser GP, Dattwyler RJ, Shapiro ED, et al. The clinical assessment, treatment, and prevention of lyme disease, human granulocytic anaplasmosis, and babesiosis: clinical practice guidelines by the Infectious Diseases Society of America. Clin Infect Dis. Nov 1; 2006 43(9):1089-1134. A. [PubMed: 17029130]

11. Nadelman RB, Wormser GP. Lyme borreliosis. Lancet. Aug 15; 1998 352(9127):557-565. [PubMed: 9716075]

12. Gerber MA, Shapiro ED, Burke GS, et al. Pediatric Lyme Disease Study Group. Lyme disease in children in southeastern Connecticut. N Engl J Med. Oct 24; 1996 335(17):1270-1274. [PubMed: 8857006]

13. Steere AC, Sikand VK, Meurice F, et al. Lyme Disease Vaccine Study Group. Vaccination against Lyme disease with recombinant Borrelia burgdorferi outer-surface lipoprotein A with adjuvant. N Engl J Med. Jul 23; 1998 339(4):209-215. [PubMed: 9673298]

14. Thompson A, Mannix R, Bachur R. Acute pediatric monoarticular arthritis; Distinguishing Lyme arthritis from other etiologies. Pediatrics. 2009; 123:959-965. [PubMed: 19255026]

15. Schlesinger PA, Duray PH, Burke BA, et al. Maternal-fetal transmission of the Lyme disease spirochete, Borrelia burgdorferi. Ann Intern Med. Jul; 1985 103(1):67-68. [PubMed: 4003991]

16. Cartter ML, Hadler JL, Gerber MA, et al. Lyme disease and pregnancy. Conn Med. Jun; 1989 53(6):341-342. [PubMed: 2758822]

17. Silver HM. Lyme disease during pregnancy. Infect Dis Clin North Am. Mar; 1997 11(1):93-97. [PubMed: 9067786]

18. Strobino BA, Williams CL, Abid S, et al. Lyme disease and pregnancy outcome: a prospective study of two thousand prenatal patients. Am J Obstet Gynecol. Aug; 1993 169(2 Pt 1):367-374. [PubMed: 8362948]

19. Gerber MA, Zalneraitis EL. Childhood neurologic disorders and Lyme disease during pregnancy. Pediatr Neurol. Jul; 1994 11(1):41-43. [PubMed: 7986291]

20. Tilly K, Rosa PA, Stewart PE. Biology of infection with Borrelia burgdorferi. Infect Dis Clin North Am. 2008; (22):217-234. [PubMed: 18452798]

21. Hovius JW, van Dam AP, Fikrig E. Tick-host-pathogen interactions in Lyme borreliosis. Trends Parasitol. Sep; 2007 23(9):434-438. [PubMed: 17656156]

22. Coleman JL, Gebbia JA, Piesman J, et al. Plasminogen is required for efficient dissemination of B. burgdorferi in ticks and for enhancement of spirochetemia in mice. Cell. Jun 27; 1997 89(7):11111119. [PubMed: 9215633]

23. Mullegger RR, McHugh G, Ruthazer R, et al. Differential expression of cytokine mRNA in skin specimens from patients with erythema migrans or acrodermatitis chronica atrophicans. J Invest Dermatol. Dec; 2000 115(6):1115-1123. [PubMed: 11121150]

24. Fikrig E, Feng W, Aversa J, et al. Differential expression of Borrelia burgdorferi genes during erythema migrans and Lyme arthritis. J Infect Dis. Oct; 1998 178(4):1198-1201. [PubMed: 9806060]

25. Krause A, Brade V, Schoerner C, et al. T cell proliferation induced by Borrelia burgdorferi in patients with Lyme borreliosis. Autologous serum required for optimum stimulation. Arthritis Rheum. Apr; 1991 34(4):393-402. [PubMed: 2012626]

26. Coburn J, Leong JM, Erban JK. Integrin alpha IIb beta 3 mediates binding of the Lyme disease agent Borrelia burgdorferi to human platelets. Proc Natl Acad Sci U S A. Aug 1; 1993 90(15): 7059-7063. [PubMed: 8394007]

27. Coburn J, Magoun L, Bodary SC, et al. Integrins alpha(v)beta3 and alpha5beta1 mediate attachment of lyme disease spirochetes to human cells. Infect Immun. May; 1998 66(5):19461952. [PubMed: 9573074]

28. Behera AK, Durand E, Cugini C, et al. Borrelia burgdorferi BBB07 interaction with integrin alpha3beta1 stimulates production of pro-inflammatory mediators in primary human chondrocytes. Cell Microbiol. Feb; 2008 10(2):320-331. [PubMed: 17822440] 
29. Guo BP, Brown EL, Dorward DW, et al. Decorin-binding adhesins from Borrelia burgdorferi. Mol Microbiol. Nov; 1998 30(4):711-723. [PubMed: 10094620]

30. Probert WS, Johnson BJ. Identification of a $47 \mathrm{kDa}$ fibronectin-binding protein expressed by Borrelia burgdorferi isolate B31. Mol Microbiol. Dec; 1998 30(5):1003-1015. [PubMed: 9988477]

31. Weis JJ, McCracken BA, Ma Y, et al. Identification of quantitative trait loci governing arthritis severity and humoral responses in the murine model of Lyme disease. J Immunol. Jan 15; 1999 162(2):948-956. [PubMed: 9916719]

32. Barthold SW, de Souza M. Exacerbation of Lyme arthritis in beige mice. J Infect Dis. Sep; 1995 172(3):778-784. [PubMed: 7658072]

33. Wooten RM, Ma Y, Yoder RA, et al. Toll-like receptor 2 is required for innate, but not acquired, host defense to Borrelia burgdorferi. J Immunol. Jan 1; 2002 168(1):348-355. [PubMed: 11751980]

34. Liu N, Montgomery RR, Barthold SW, et al. Myeloid differentiation antigen 88 deficiency impairs pathogen clearance but does not alter inflammation in Borrelia burgdorferi-infected mice. Infect Immun. Jun; 2004 72(6):3195-3203. [PubMed: 15155621]

35. Kelleher Doyle M, Telford SR 3rd, Criscione L, et al. Cytokines in murine lyme carditis: Th1 cytokine expression follows expression of proinflammatory cytokines in a susceptible mouse strain. J Infect Dis. Jan; 1998 177(1):242-246. [PubMed: 9419199]

36. Barthold SW, Feng S, Bockenstedt LK, et al. Protective and arthritis-resolving activity in sera of mice infected with Borrelia burgdorferi. Clin Infect Dis. Jul; 1997 25(Suppl 1):S9-17. [PubMed: 9233658]

37. Roberts ED, Bohm RP Jr. Lowrie RC Jr. et al. Pathogenesis of Lyme neuroborreliosis in the rhesus monkey: the early disseminated and chronic phases of disease in the peripheral nervous system. J Infect Dis. Sep; 1998 178(3):722-732. [PubMed: 9728541]

38. Cadavid D, O'Neill T, Schaefer H, et al. Localization of Borrelia burgdorferi in the nervous system and other organs in a nonhuman primate model of lyme disease. Lab Invest. Jul; 2000 80(7):10431054. [PubMed: 10908149]

39. Steere AC, Duray PH, Butcher EC. Spirochetal antigens and lymphoid cell surface markers in Lyme synovitis. Comparison with rheumatoid synovium and tonsillar lymphoid tissue. Arthritis Rheum. Apr; 1988 31(4):487-495. [PubMed: 3258751]

40. Akin E, McHugh GL, Flavell RA, et al. The immunoglobulin (IgG) antibody response to OspA and $\mathrm{OspB}$ correlates with severe and prolonged Lyme arthritis and the IgG response to P35 correlates with mild and brief arthritis. Infect Immun. Jan; 1999 67(1):173-181. [PubMed: 9864212]

41. Vincent MS, Roessner K, Sellati T, et al. Lyme arthritis synovial gamma delta T cells respond to Borrelia burgdorferi lipoproteins and lipidated hexapeptides. J Immunol. Nov 15; 1998 161(10): 5762-5771. [PubMed: 9820558]

42. Chen J, Field JA, Glickstein L, et al. Association of antibiotic treatment-resistant Lyme arthritis with $\mathrm{T}$ cell responses to dominant epitopes of outer surface protein A of Borrelia burgdorferi. Arthritis Rheum. Sep; 1999 42(9):1813-1822. [PubMed: 10513794]

43. Gross DM, Steere AC, Huber BT. T helper 1 response is dominant and localized to the synovial fluid in patients with Lyme arthritis. J Immunol. Jan 15; 1998 160(2):1022-1028. [PubMed: 9551943]

44. Yin Z, Braun J, Neure L, et al. T cell cytokine pattern in the joints of patients with Lyme arthritis and its regulation by cytokines and anticytokines. Arthritis Rheum. Jan; 1997 40(1):69-79. [PubMed: 9008602]

45. Dressler F, Whalen JA, Reinhardt BN, Steere AC. Western blotting in the serodiagnosis of Lyme disease. J Infect Dis. Feb; 1993 167(2):392-400. [PubMed: 8380611]

46. Steere AC, Levin RE, Molloy PJ, et al. Treatment of Lyme arthritis. Arthritis Rheum. Jun; 1994 37(6):878-888. [PubMed: 8003060]

47. Steere AC, Klitz W, Drouin EE, et al. Antibiotic-refractory Lyme arthritis is associated with HLADR molecules that bind a Borrelia burgdorferi peptide. J Exp Med. Apr 17; 2006 203(4):961-971. [PubMed: 16585267] 
48. Shapiro ED. Lyme disease in children. Am J Med. Apr 24; 1995 98(4A):69S-73S. [PubMed: 7726195]

49. Centers for Disease Control and Prevention. Recommendations for test performance and interpretation from the Second National Conference on Serologic Diagnosis of Lyme Disease. MMWR. 1995; (44):590-591. B. [PubMed: 7623762]

50. Seltzer EG, Shapiro ED. Misdiagnosis of Lyme disease: when not to order serologic tests. Pediatr Infect Dis J. Sep; 1996 15(9):762-763. [PubMed: 8878216]

51. Tugwell P, Dennis DT, Weinstein A, et al. Laboratory evaluation in the diagnosis of Lyme disease. Ann Intern Med. Dec 15; 1997 127(12):1109-1123. [PubMed: 9412316]

52. Steere AC, Sikand VK. The presenting manifestations of Lyme disease and the outcomes of treatment. N Engl J Med. Jun 12; 2003 348(24):2472-2474. [PubMed: 12802042]

53. Feder HM Jr. Gerber MA, Luger SW, et al. Persistence of serum antibodies to Borrelia burgdorferi in patients treated for Lyme disease. Clin Infect Dis. Nov; 1992 15(5):788-793. [PubMed: 1445977]

54. Kalish RA, McHugh G, Granquist J, et al. Persistence of immunoglobulin M or immunoglobulin G antibody responses to Borrelia burgdorferi 10-20 years after active Lyme disease. Clin Infect Dis. Sep 15; 2001 33(6):780-785. [PubMed: 11512082]

55. Ljostad U, Skogvoll E, Eikeland R, et al. Oral doxycycline versus intravenous ceftriaxone for European Lyme neuroborreliosis: a multicentre, non-inferiority, double-blind, randomised trial. Lancet Neurol. Aug; 2008 7(8):690-695. A. [PubMed: 18567539]

56. Mullegger RR, Millner MM, Stanek G, et al. Penicillin G sodium and ceftriaxone in the treatment of neuroborreliosis in children--a prospective study. Infection. Jul-Aug;1991 19(4):279-283. [PubMed: 1917046]

57. Klempner MS, Hu LT, Evans J, et al. Two controlled trials of antibiotic treatment in patients with persistent symptoms and a history of Lyme disease. N Engl J Med. Jul 12; 2001 345(2):85-92. A. [PubMed: 11450676]

58. Ettestad PJ, Campbell GL, Welbel SF, et al. Biliary complications in the treatment of unsubstantiated Lyme disease. J Infect Dis. Feb; 1995 171(2):356-361. [PubMed: 7844372]

59. Feder HM Jr. Johnson BJ, O'Connell S, et al. A critical appraisal of "chronic Lyme disease". N Engl J Med. Oct 4; 2007 357(14):1422-1430. [PubMed: 17914043]

60. Vazquez M, Muehlenbein C, Cartter M, et al. Effectiveness of personal protective measures to prevent Lyme disease. Emerg Infect Dis. Feb; 2008 14(2):210-216. [PubMed: 18258112]

61. Brei B, Brownstein JS, George JE, et al. Evaluation of the United States Department Of Agriculture Northeast Area-wide Tick Control Project by meta-analysis. Vector Borne Zoonotic Dis. Aug; 2009 9(4):423-430. [PubMed: 19650737]

62. Shapiro ED. Doxycycline for tick bites--not for everyone. N Engl J Med. Jul 12; 2001 345(2):133134. [PubMed: 11450662] 


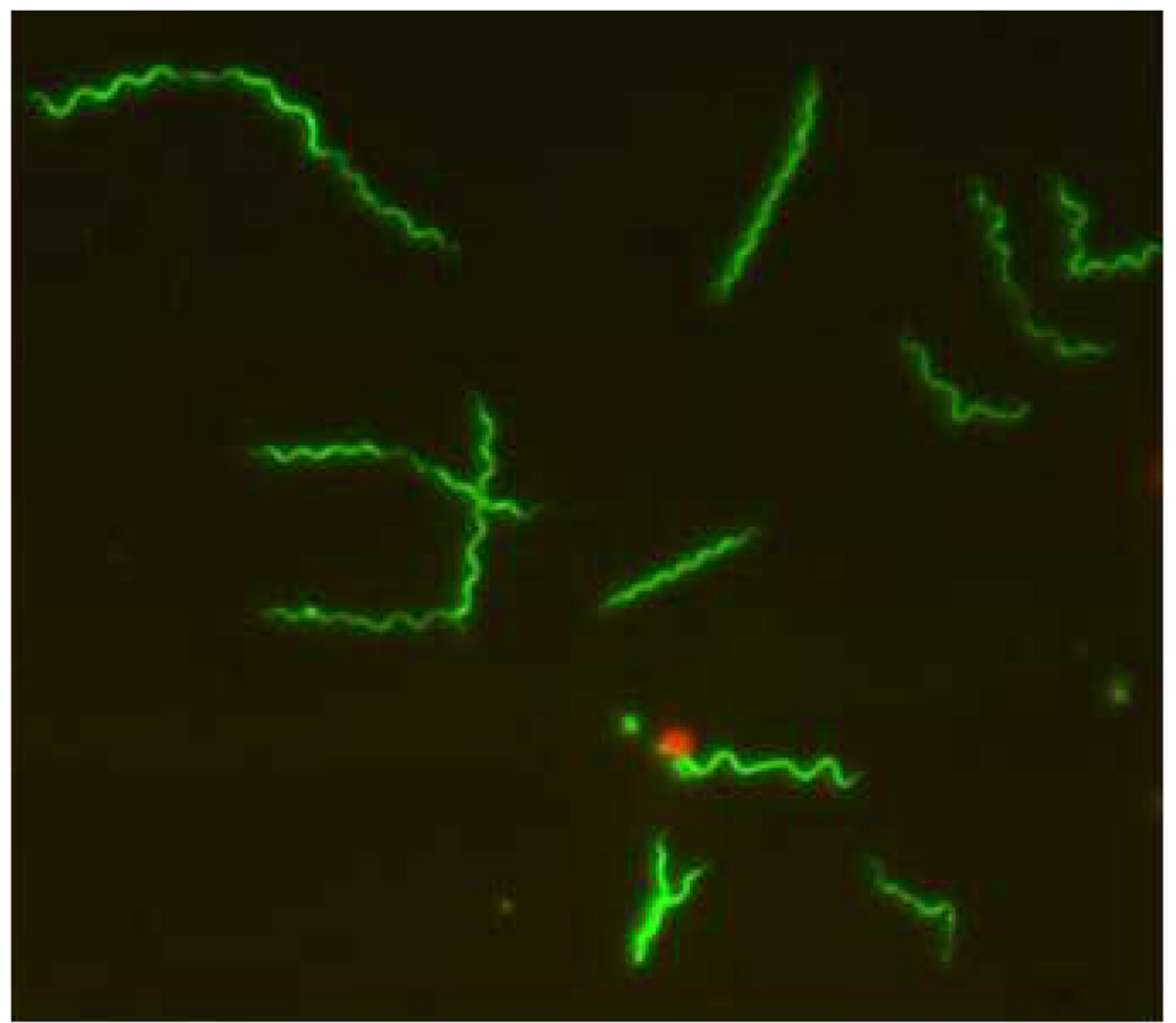

Figure 1.

Borrellia burgdorferi, infective bacterium of Lyme disease. The spirochete is stained with Syto 9 and visualized with fluorescent microscopy. Courtesy of Sarojini Adusumilli. 


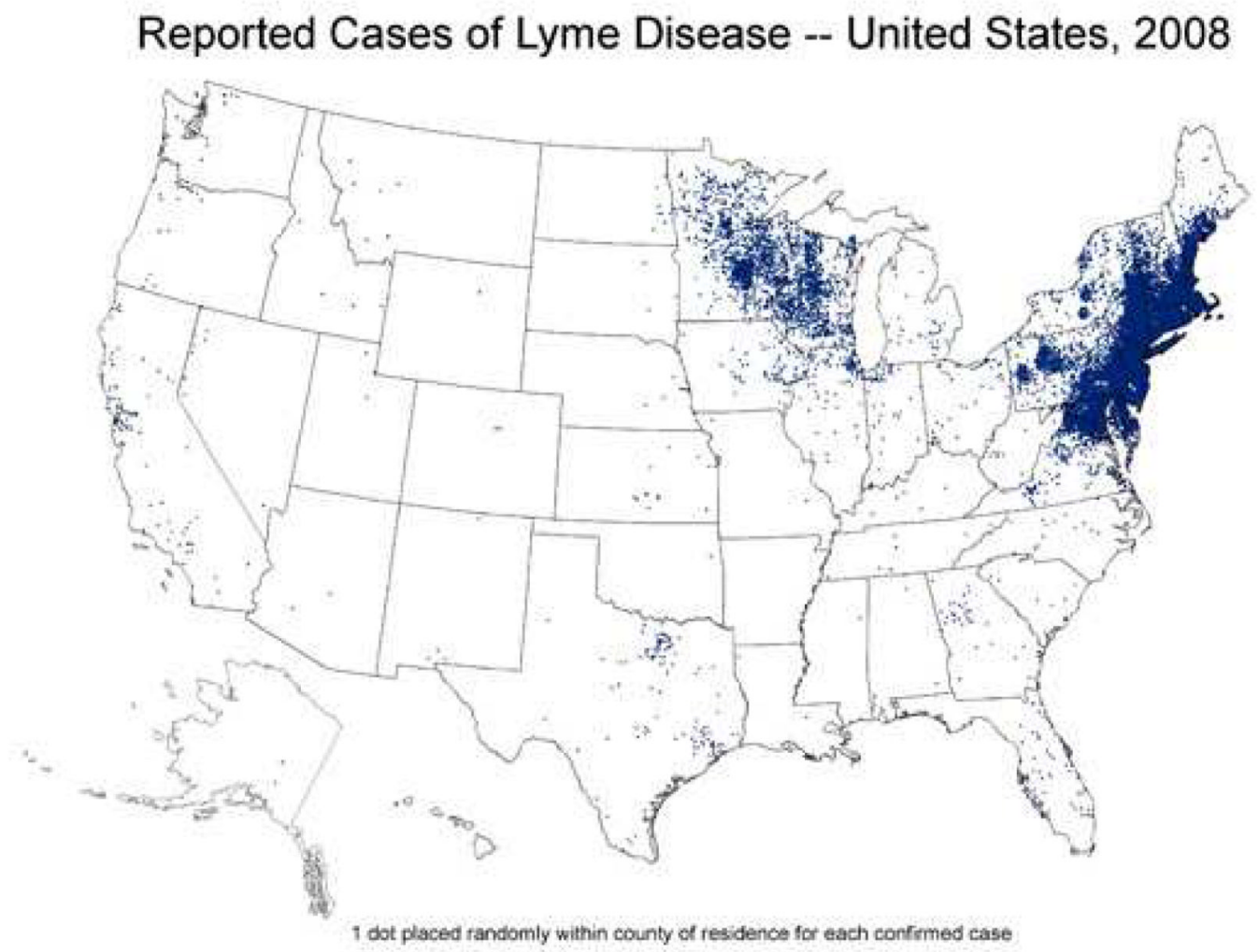

Figure 2.

Epidemiology of Lyme Disease. The distribution of disease corresponds to the distribution of the Ixodes ticks that transmit B. burgdorferi. 

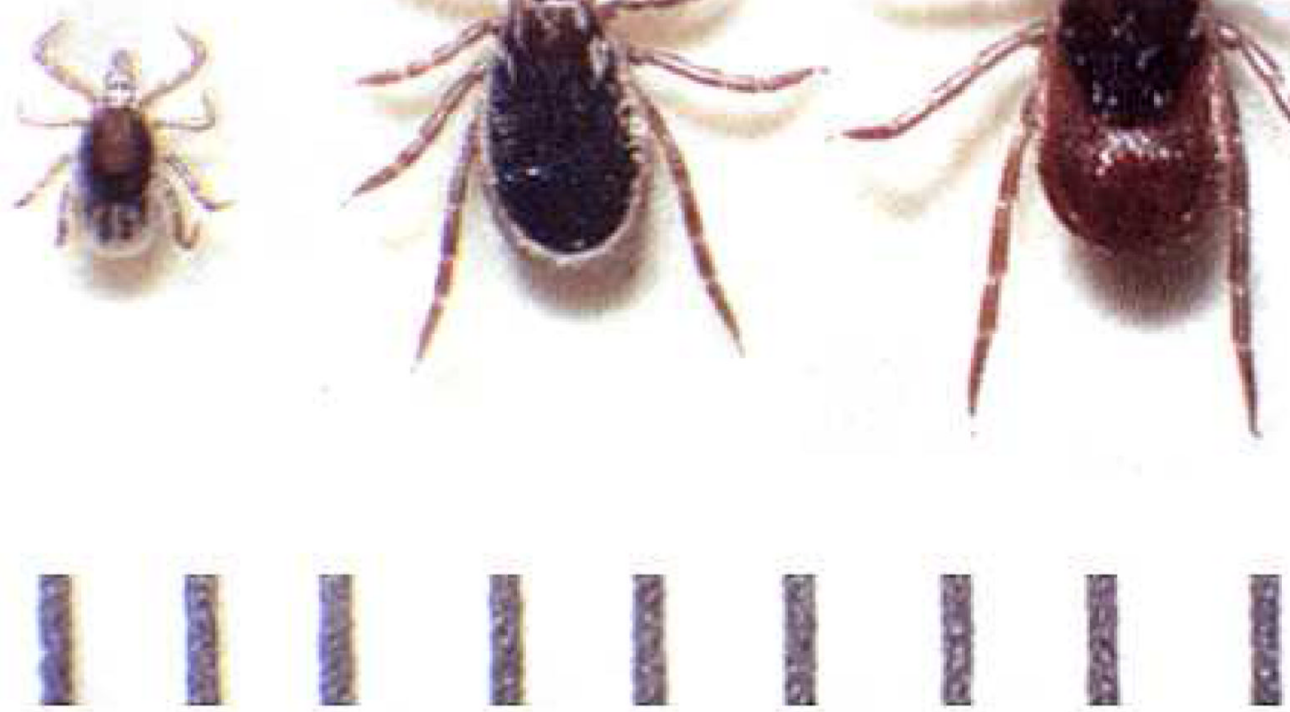

Figure 3.

Various stages of the life cycle of the deer tick Ixodes scapularis, the vector for Lyme disease in the northern United States. The larval stage is shown on the left, followed by the nymphal stage, the adult female, and the adult male on the right. Most infections are transmitted from ticks at the nymphal stage. 


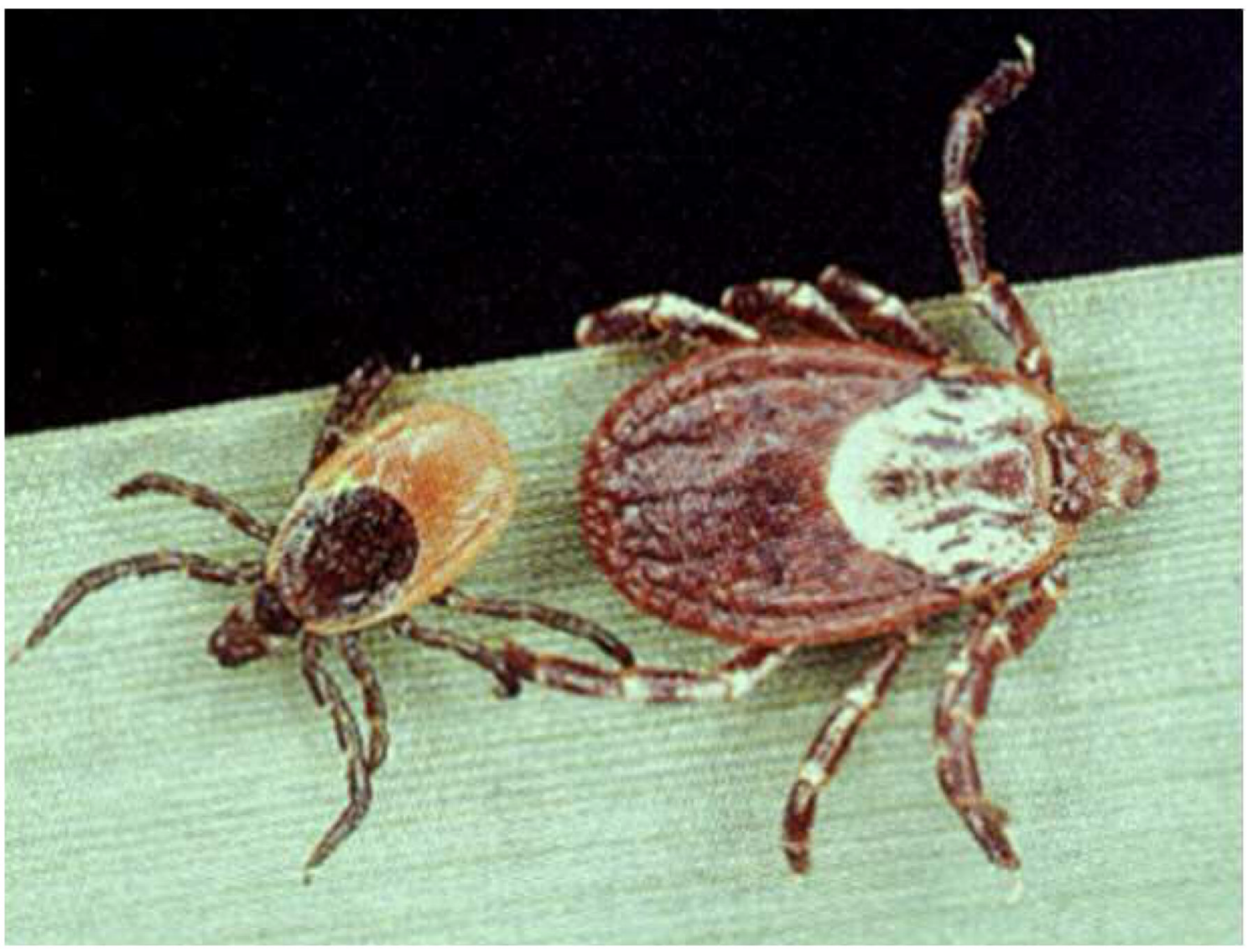

Figure 4.

A comparison of the deer tick Ixodes scapularis, on the left, with the dog tick Dermacentor variabilis, on the right. Typically, dog ticks are much larger than deer ticks. 


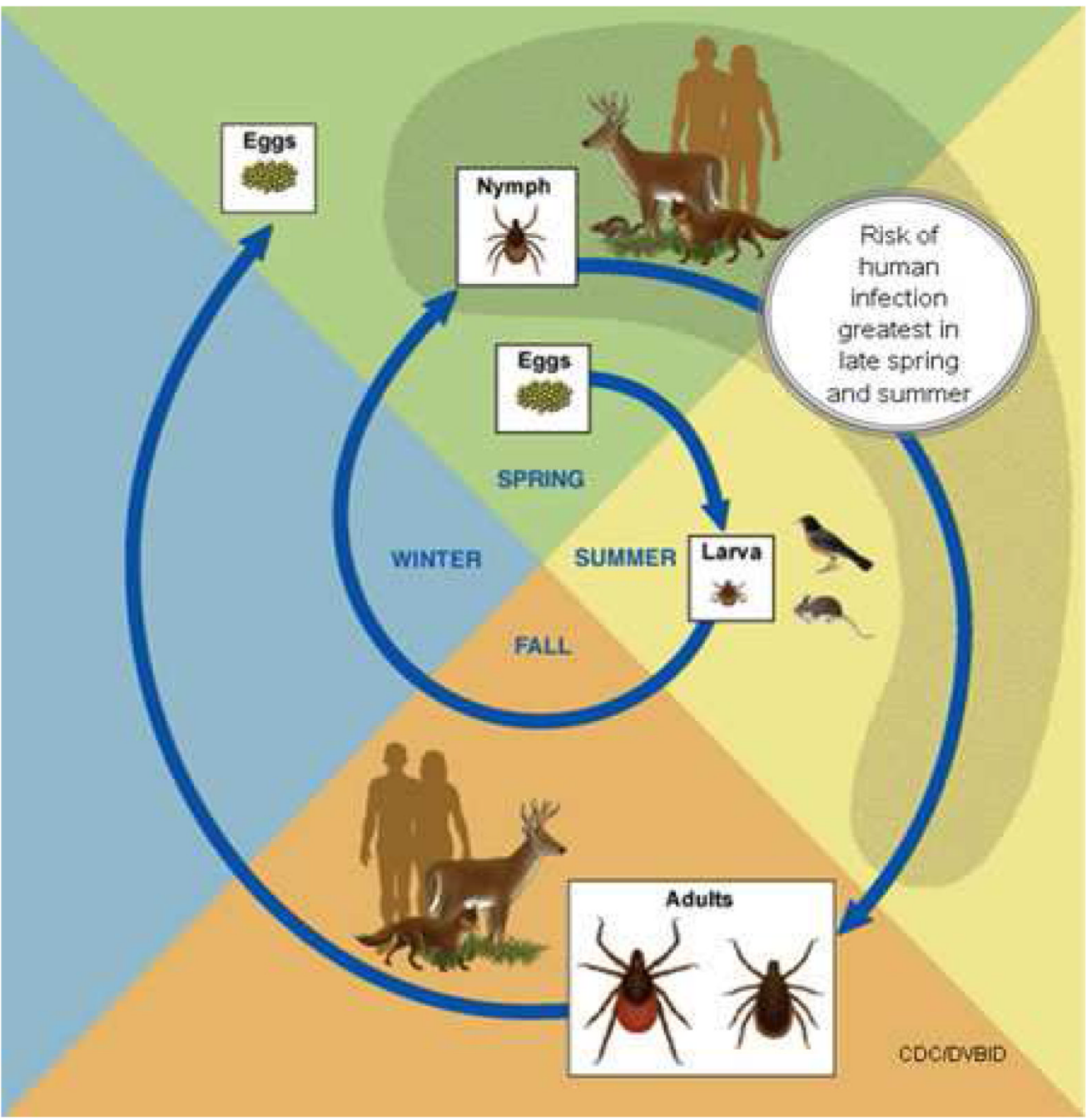

Figure 5.

Two-year lifecycle of Ixodid ticks. Larvae hatch in the summer when they may feed on a small mammal infected with $B$. burgdorferi. The larvae survive the winter and emerge the following spring as nymphs, when they are most likely to transmit infection. The nymphs molt to become adults in the fall, attach to large animals during the winter, and the females lay eggs the following spring. (CDC Open access photo) 


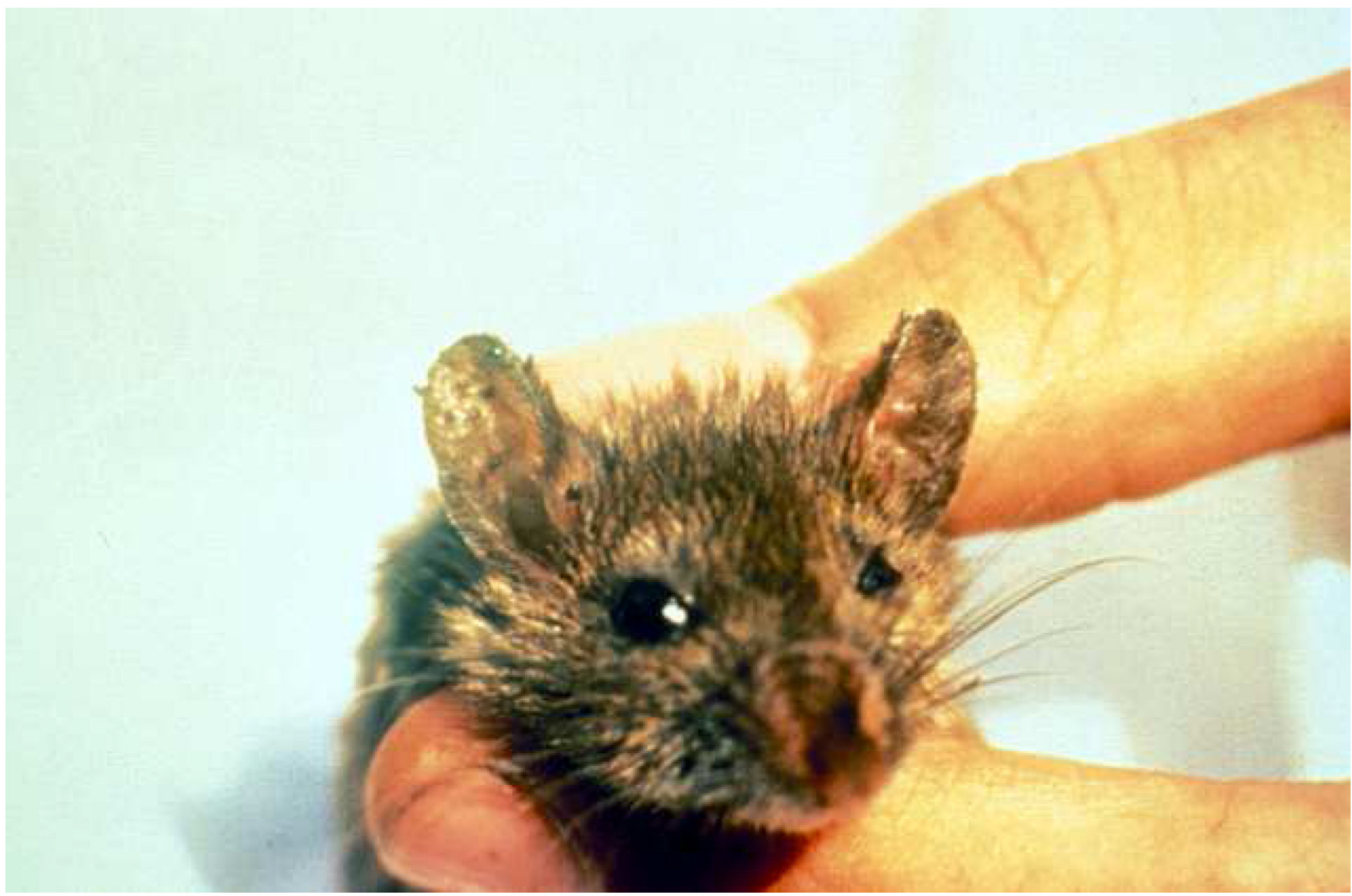

Figure 6.

The white footed mouse (Peromyscus leucopus) is a reservoir for Ixodes scapularis. Note the large numbers of ticks attached to this mouse. 


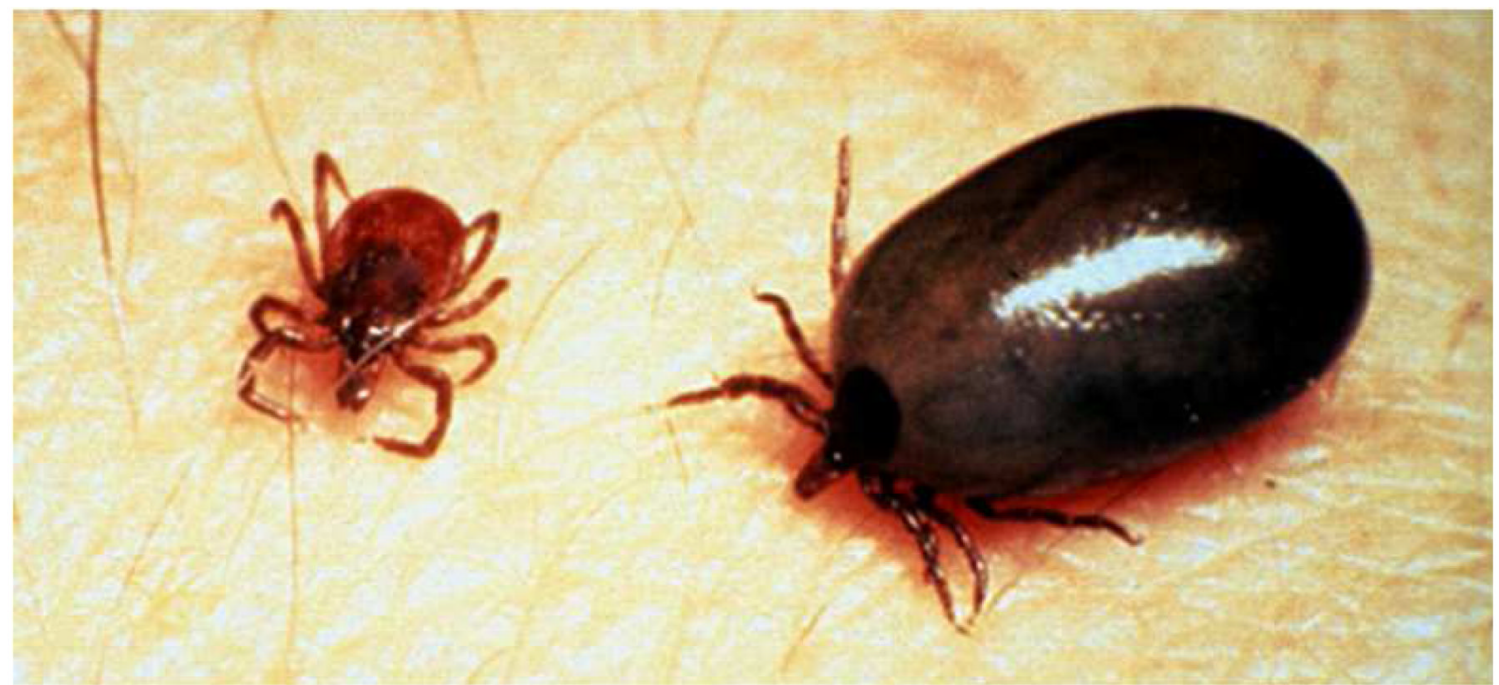

Figure 7.

An engorged Ixodid scapularis tick. Ticks become engorged after 48-72 hours. Ticks removed prior to this time, before they become engorged, rarely transmit Lyme disease. 

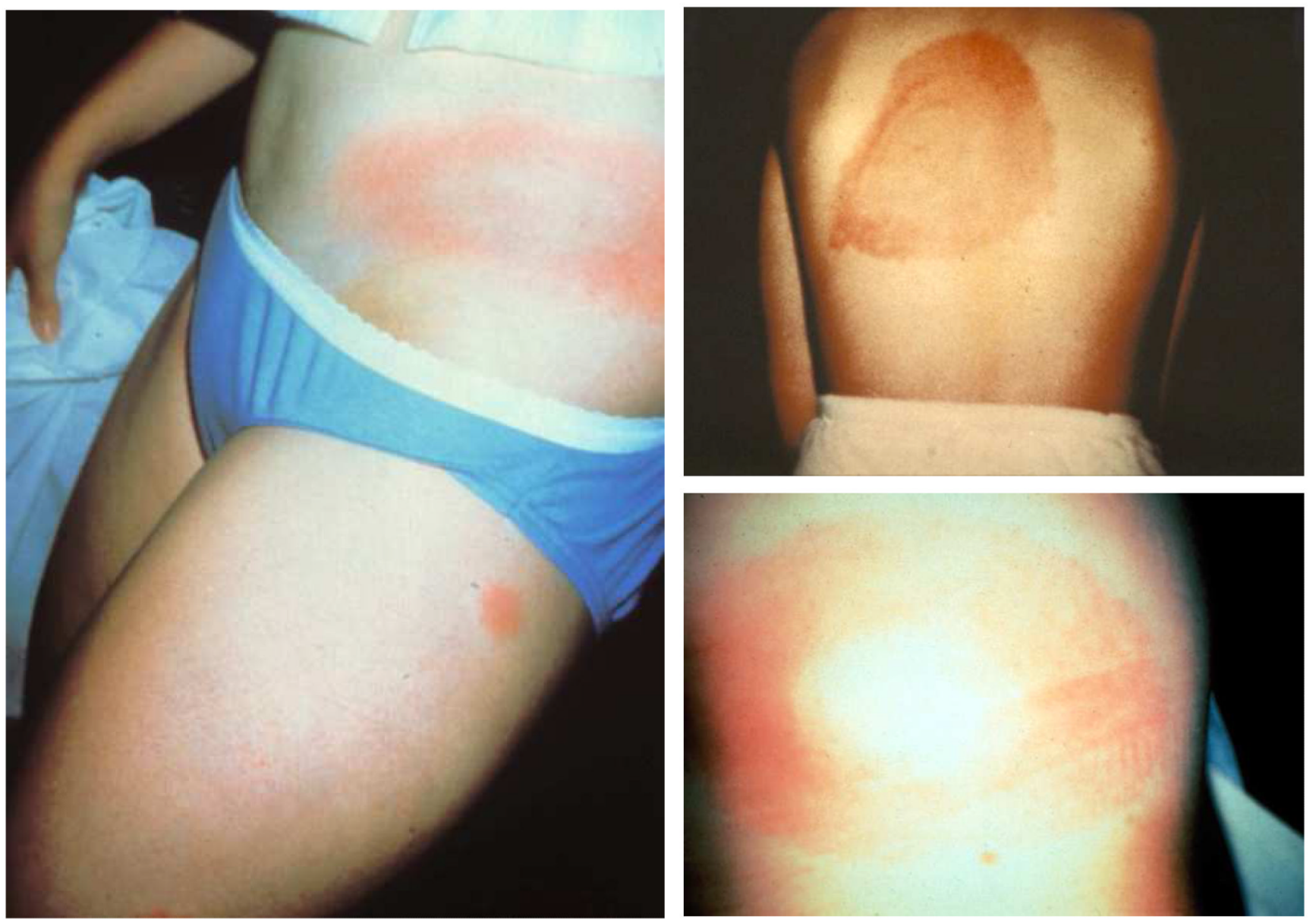

Figure 8.

Erythema migrans. This rash is the characteristic lesion of early Lyme disease. It may be appear as a target-like lesion with central clearing or may be erythematous throughout. 


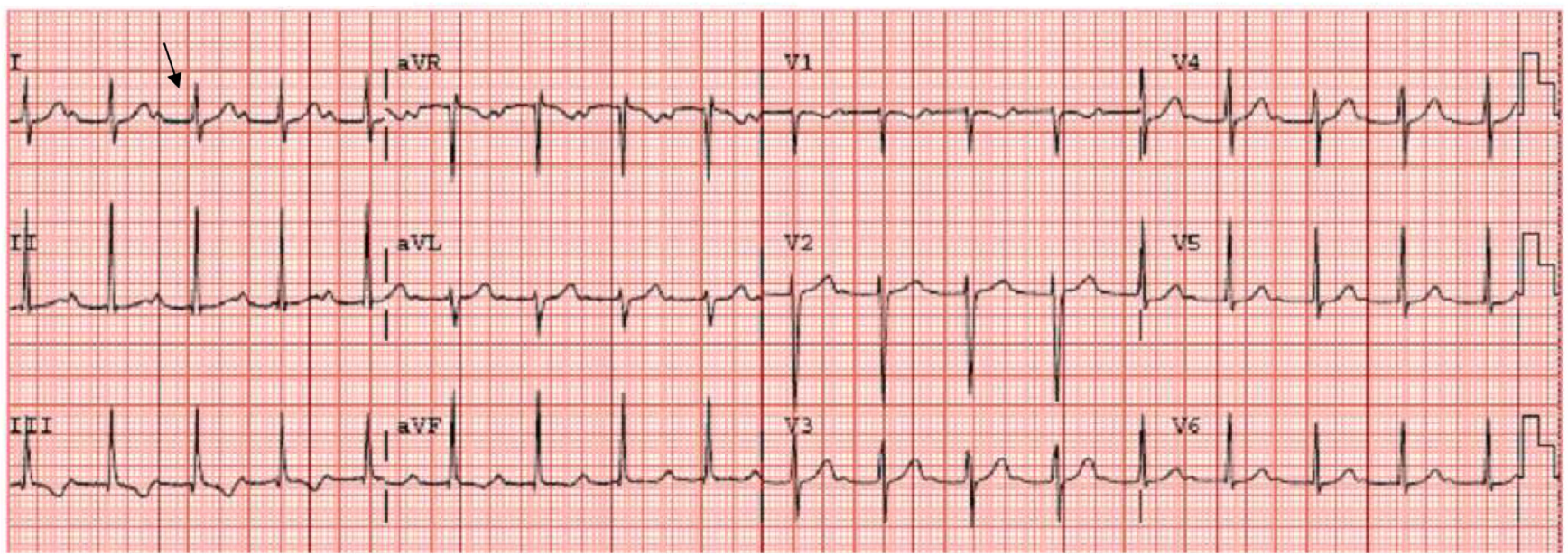

Figure 9.

Prolonged PR interval from Lyme carditis. This EKG is was performed on a 9 yr old child from a Lyme endemic area with known tick exposures who presented with a history of fever, flu-like symptoms, and syncope. His PR interval (shown by the arrow) was 0.548 (nl 0.12-0.2) consistent with first degree heart block. He was admitted to the hospital and placed on ceftriaxone therapy. His symptoms improved after three days and he was discharged home on doxycycline to complete 21 days of antimicrobial therapy. 


\section{Western Immunoblot}

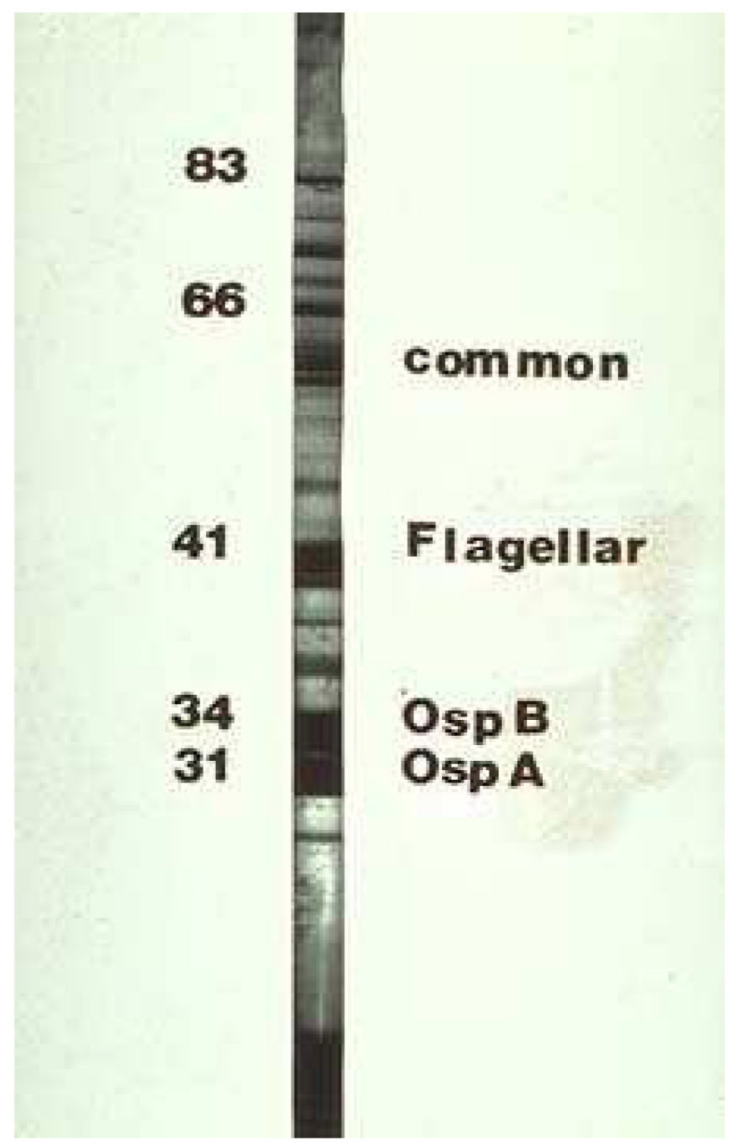

Figure 10.

IgG immunoblot used to aid in the diagnosis of Lyme disease. Immunoblots are indicated after a positive ELISA from a patient with a clinical syndrome consistent with Lyme disease. The criteria for a positive IgG immunoblot are the presence of 5 bands. In patients with erythema migrans, the immunoblot can initially be negative prior to the development of antibodies against B.burgdorferi. 
Table 1

\section{Clinical Presentations and Therapy for Lyme disease}

\begin{tabular}{|c|c|c|c|}
\hline $\begin{array}{l}\text { Disease } \\
\text { Stage }\end{array}$ & $\begin{array}{l}\text { Clinical } \\
\text { Manifestations }\end{array}$ & Treatment & Duration \\
\hline $\begin{array}{l}\text { Early } \\
\text { localized }\end{array}$ & Erythema migrans & Oral & 14-21 days \\
\hline \multirow[t]{5}{*}{$\begin{array}{l}\text { Early } \\
\text { disseminated }\end{array}$} & $\begin{array}{l}\text { Multiple erythema } \\
\text { migrans }\end{array}$ & Oral & 14-21 days \\
\hline & $\begin{array}{l}\text { Isolated cranial nerve } \\
\text { palsy }\end{array}$ & Oral & 14-21 days \\
\hline & $\begin{array}{l}\text { Meningoradiculoneuritis } \\
\text { Meningitis }\end{array}$ & $\begin{array}{l}\text { Intravenous } \\
\text { or Oral }\end{array}$ & $\begin{array}{l}10-28 \text { days } \\
14-21 \text { days }\end{array}$ \\
\hline & $\begin{array}{l}\text { Carditis } \\
\text { Ambulatory } \\
\text { Hospitalized }\end{array}$ & $\begin{array}{l}\text { Oral } \\
\text { Intravenous * } \\
\text { followed by } \\
\text { oral }\end{array}$ & $\begin{array}{l}\text { 14-21 days } \\
14-21 \text { days }\end{array}$ \\
\hline & Borrelial lymphocytoma & Oral & 14-21 days \\
\hline \multirow[t]{4}{*}{ Late } & Arthritis & Oral & 28 days \\
\hline & $\begin{array}{l}\text { Recurrent arthritis after } \\
\text { oral therapy }\end{array}$ & $\begin{array}{l}\text { Oral or } \\
\text { Intravenous }\end{array}$ & $\begin{array}{l}28 \text { days } \\
14-28 \text { days }\end{array}$ \\
\hline & Encephalitis & Intravenous & 14-28 days \\
\hline & $\begin{array}{l}\text { Acrodematitis chronica } \\
\text { atrophicans }\end{array}$ & Oral & 14-28 days \\
\hline
\end{tabular}

At the time of discharge, the patient may receive oral medication to complete therapy 
Table 2

Predictive value of serologic tests vary by disease prevalence

\begin{tabular}{|c|l|l|l|l|}
\hline $\begin{array}{c}\text { Disease } \\
\text { Prevalence }\end{array}$ & Test Result & $\begin{array}{l}\text { Disease } \\
\text { present }\end{array}$ & $\begin{array}{l}\text { Disease } \\
\text { Absent }\end{array}$ & Total \\
\hline \multirow{2}{*}{$1 \%$} & Positive & 95 & 990 & 1085 \\
\cline { 2 - 5 } & Negative & 5 & 8910 & 8915 \\
\cline { 2 - 5 } & Total & 100 & 9900 & 10,000 \\
\cline { 2 - 5 } & $\begin{array}{l}\text { Predictive } \\
\text { value }\end{array}$ & $\mathbf{8 . 8 \%}$ & $\mathbf{9 9 . 9 \%} *$ & \\
\hline \multirow{2}{*}{$10 \%$} & Positive & 950 & 900 & 1850 \\
\cline { 2 - 5 } & Negative & 50 & 8100 & 8150 \\
\cline { 2 - 5 } & Total & 1000 & 9000 & 10,000 \\
\cline { 2 - 5 } & $\begin{array}{l}\text { Predictive } \\
\text { value }\end{array}$ & $\mathbf{5 1 . 4 \%}$ & $\mathbf{9 9 . 4 \%} *$ & \\
\hline
\end{tabular}

In each case the test is $95 \%$ sensitive and $90 \%$ specific.

\# Predictive value of a positive test

* Predictive value of a negative test 
Table 3

Antibiotic regimens for Lyme disease

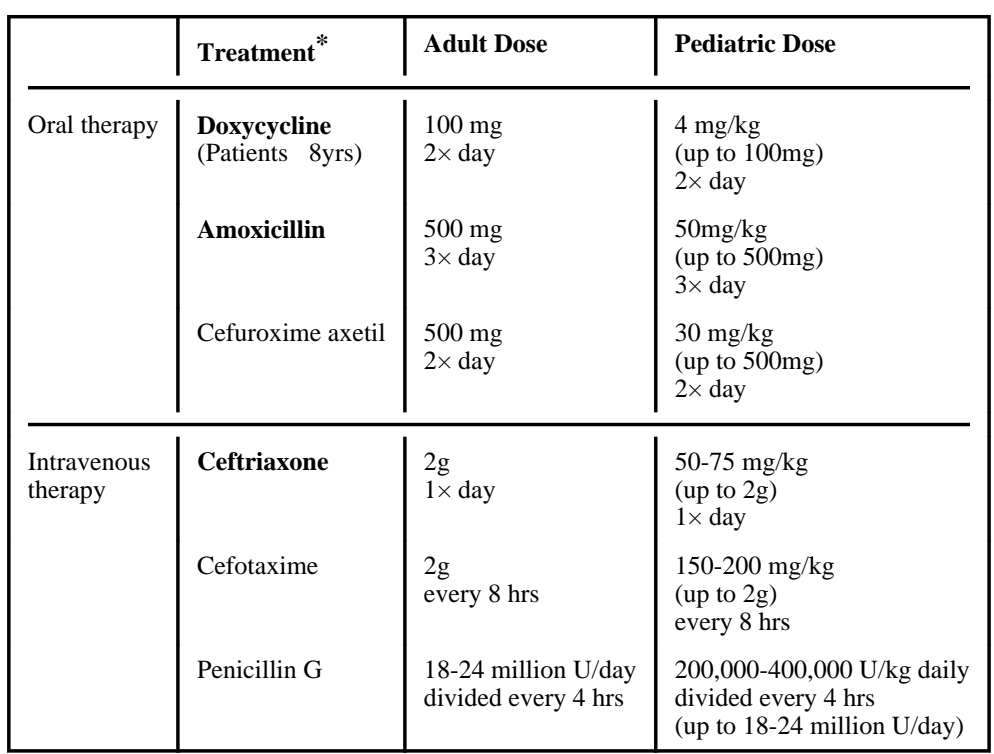

Most commonly used antibiotics are in bold. 